SEP U R REC'D

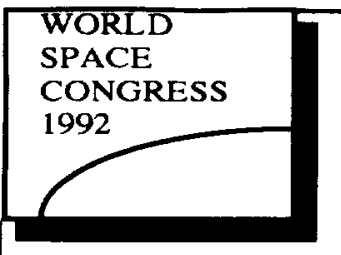

$$
\begin{aligned}
& \text { (NASA-CP-192052) A METHODULUGY FOR } \\
& \text { SFLECTIVE REHNVAL OF ORSITAL OERRIS } \\
& \text { (I) Dorinion Univ.) } 14 \mathrm{p}
\end{aligned}
$$

B.8-M.2.18X

\title{
A Methodology for Selective Removal of Orbital Debris
}

R. L. Ash, P. J. O'Donoghue and E. J. Chambers

Old Dominion University

Norfolk, VA

\section{J. P. Raney}

West Virginia Institute of Technology

Montgomery, WV 


\title{
B.8-M.2.18X
}

\section{A METHODOLOGY FOR SELECTIVE REMOVAL OF ORBITAL DEBRIS}

\author{
by
}

\author{
R. L. Ash*, P. J. O'Donoghue*, \\ E. J. Chambers* and J. P. Raney*"
}

\begin{abstract}
Earth-orbiting objects, large enough to be tracked, have been surveyed for possible systematic debris removal. Based upon the statistical collision studies of others, it was determined that objects in orbits approximately $1000 \mathrm{~km}$ above the Earth's surface are at greatest collisional risk. This study has identified Russian C-1B boosters as the most important target of opportunity for debris removal. Currently, more than 100 in tact boosters are orbiting the Earth with apogees between $950 \mathrm{~km}$ and $1050 \mathrm{~km}$. Using data provided by Energia USA, specific information on the C-1B booster, in terms of rendezvous and capture strategies, has been discussed.
\end{abstract}

\section{Introduction}

Space Station Freedom is expected to occupy a low Earth orbit for several decades. In order for it to operate safely for that length of time, it must avoid collisions with spaceborne objects - primarily man-made debris. Because of its large size, micrometeoroid impacts will occur on space structural elements regularly. However, collisions with larger objects must be avoided and the removal of significant quantities of debris source material will be desirable to insure safe operation. The goal of this paper is to describe a methodology for identifying and removing strategic debris elements.

\footnotetext{
- Mechanical Engineering and Mechanics Department, Old Dominion University, Norfolk, VA 23529-0247

** Mechanical Engineering Department, West Virginia Institute of Technology, Montgomery, WV 25136
} 
A recent Space Station Freedom study $/ 1 /$ has indicated that for objects larger than $2 \mathrm{~mm}$, collision probabilities are higher for man-made debris than for naturally occurring material. That study estimated that approximately $200 \mathrm{~kg}$ of natural debris were present typically within $2000 \mathrm{~km}$ of the Earth's surface at any particular time. That mass compares with approximately $3,000,000 \mathrm{~kg}$ of man-made material existing currently in Earth orbit. The study estimated that the most probable collision velocity between space station (target) and man-made debris was $13 \mathrm{~km} / \mathrm{s}$ - nearly a head-on collision. At that collision speed, Ramohalli $/ 2 /$ has pointed out that a $1.8 \mathrm{~cm}$ diameter aluminum pellet carries the same impact kinetic energy as a mid-size automobile travelling at $100 \mathrm{~km} / \mathrm{hr}$.

NASA's Long Duration Exposure Facility experienced more than 34,000 micrometeoroid impacts during its $5.78 \mathrm{yr}$ orbital life, but the largest impacting object had an estimated size of 1 $\mathrm{mm}$ (and produced a $5 \mathrm{~mm}$ diameter crater, $/ 3 /$ ). Butner and Gartrell $/ 3 /$ have reported that most of the impacting debris was believed to be man-made (paint flecks, propulsion system residue, etc.). Furthermore, laboratory tests which simulated collisions between small objects (150 g) travelling at speeds up to $6 \mathrm{~km} / \mathrm{s}$ with a small $(54 \mathrm{~kg}$ ) navigation satellite produced millions of small particles /4/. Since it is not feasible to collect space debris in such quantities after a collision, it is essential to collect and remove the larger objects before they collide. Ramohalli /2/ has discussed the consequences of the November 1986, breakup of an Ariane upper stage. That material ultimately becomes distributed over a large orbital volume, leading potentially to more collisions.

Kessler $15,6 /$ has been characterizing the orbital debris hazard for a considerable period of time. Those studies have shown that the possibility of a catastrophic collisional cascade is increasing and that the population of man-made objects with orbital altitudes between $900 \mathrm{~km}$ and $1000 \mathrm{~km}$ is already sufficient to be considered unstable. Ramohalli and co-workers $/ 2,7,8 /$ 
have advocated an aggressive debris removal program, considering methods for collecting and retrieving the material. Alternate approaches have been considered by Grumman Corp. 19/.

The current study has taken a somewhat different approach. Rather than attempting to design a general-purpose debris removal system, the project team elected to investigate the known population of orbiting objects to determine whether a single class of debris could be identified for removal by a single-purpose system. Orbital debris was defined as all orbiting objects which were no longer performing a useful function in orbit (dead satellites, rocket stages and fragments). The methodology which was employed to identify a primary target of opportunity is reported herein.

\section{Satellite Population Classification and Selection}

NASA Goddard Space Flight Center compiles satellite situation reports at regular intervals. In September 1990, their NASA Satellite Situation Report listed 6,681 items that were being tracked. Actually, that list understates the true population of large objects. For example, an item listed as Cosmos 1220, which was launched by the Soviet Union in 1980 and destroyed intentionally, produced at least 80 pieces of debris /10/ of which 59 were still being tracked. It was listed as two items (1980 089A - Cosmos 1220 satellite - and 1980 089B-089CG which represented the remaining 58 pieces). However, since retrieval of large objects from a swarm of smaller objects would be too hazardous for a debris removal system, this study was not concerned about the true total satellite count. Rather, the goal was to define orbiting subsets which were truly near-term debris removal targets of opportunity.

Based upon Kessler's collisional cascade predictions $/ 6 /$, this study focused on large objects with initial orbital altitudes, at perigee, in the $700 \mathrm{~km}$ to $1500 \mathrm{~km}$ altitude range. The upper altitude limit was selected since many of the higher altitude objects had degraded to lower altitudes (on the order of $1000 \mathrm{~km}$ ) after launch. Then using the RAE satellite tables $/ 11 /$, along 
with the Goddard satellite situation reports, objects could be categorized in terms of their type and size. The orbiting objects in the $1000 \mathrm{~km}$ altitude interval category were Soviet, mostly with orbital inclinations near $83^{\circ}$ (between $70^{\circ}$ and $85^{\circ}$ ). Using the data compiled by Johnson $/ 12$, 13/ as representative and therefore focusing on 1987 and 1988 data as being the most complete, 162 separate orbiting objects were categorized. Those data are summarized in Table I. Since the listed Soviet satellites were likely to be complicated shapes, and in many cases are operational, they were eliminated as possible targets.

From the table, it can be seen that rocket bodies constituted approximately 75 percent of the identified mass orbiting near $1000 \mathrm{~km}$ altitude (launched in 1987 and 1988) and that the Soviet C-1B second stage (U.S. D.o.D. designation is SL-8) represented approximately 75 percent of the rocket body population. Consequently, the data search was expanded to include all Soviet Cosmos launches through June 1990. A total of 245 rocket bodies were identified as being in orbit. Of that number, 204 were identified as C-1B boosters.

Since rocket bodies surrounded by orbiting debris were likely to be damaged - making retrieval more difficult and dangerous - those rocket bodies were eliminated as potential targets. The number of "undamaged" rocket body targets was thereby reduced from 245 to 193 . Unfortunately, the particular type of rocket body in orbit has not been identified consistently in the data sets.

Faranetta /14/ has reported that NPO Energia, in Russia, made preliminary studies of removing debris from geostationary orbits using an orbital maneuvering vehicle and an Energia Heavy-lift launch vehicle. In addition, through the cooperation of Energia USA, this study has been able to acquire additional details on the orbiting rocket bodies in lower Earth orbits. Dr. Boris I. Gubanov was a primary designer of both Cosmos and Cyclone (DoD designated 
SL-14) boosters, as well as the Energia booster, and has assisted Energia USA in cooperating with us.

The Cosmos second stage (C-1B) is listed as being $7.5 \mathrm{~m}$ in length and $2.4 \mathrm{~m}$ in diameter. The original design utilized a single nozzle, RD-119, motor. The nozzle diameter was $1.02 \mathrm{~m}$ and extended $0.6 \mathrm{~m}$ behind the second stage tanks. Apparently, the second stage could be modified to accommodate a twin nozzle, RD-219, engine (which was used on the Cyclone booster and generated $900 \mathrm{kN}$ thrust), but it is not clear which, if any, recent rocket bodies were modified. For the purposes of the present study, all rocket bodies which were either designated as SL-8's or which were listed as having an orbiting mass of $2200 \mathrm{~kg}$ with lengths and diameters of 7.5 $\mathrm{m}$ and $2.4 \mathrm{~m}$, respectively were classified as C-1B's. There were 158, out of 193 in tact rocket bodies, that were designated as C-1B's.

Ramohalli et al. $/ 7 /$ have discussed how orbital inclinations can be varied for an orbiting debris removal system via nodal regression. They also investigated optimal trajectories for multiple debris removal operation $\Pi, 8 /$. Here, it was decided that rocket body removal could be accomplished most efficiently by seeking clusters of rocket bodies that were located within a narrow band of inclinations and altitudes.

It was determined that $100 \mathrm{C}$-1B rocket bodies were located at orbital inclination of between $82.9^{\circ}$ and $83.0^{\circ}$, with apogees between 950 and $1050 \mathrm{~km}$. In fact, referring to Figure 1,56 of the rocket bodies were orbiting in an apogee band of $20 \mathrm{~km}$. The high density of orbiting rocket bodies has been produced by the requirements for the Cosmos navigation system. Those navigation satellites are placed in orbit at an approximate rate of one every $13.5 \mathrm{mo}$. for the military system and one every 30 mo. for the civilian system. While the Cosmos navigation system was scheduled for phase out by the year 2000 , the population of rocket bodies, produced by their launch, is already large and is likely to increase. 


\section{Debris Removal Methodology}

This study has shown that a debris removal system which was designed to acquire and remove Soviet C-1B rocket bodies at an orbital inclination of $83^{\circ}$, with apogee altitudes near 1000 $\mathrm{km}$, could remove more than $200,000 \mathrm{~kg}$ of debris and reduce the possibility of a catastrophic collisional cascade in the $1000 \mathrm{~km}$ orbital altitude range significantly. Since these C-1B rocket bodies are mostly aluminum and of limited value, the most straightforward method for removal would be to rendezvous with the (tumbling) body, despin it and orient it for reentry. Then, taking advantage of the fact that the existing rocket motor is already aligned with the center of gravity of the booster, a small solid-propellant rocket could be designed which could be inserted into the existing nozzle and fired to reenter the rocket body back into the atmosphere and scatter any surviving reentry material over the ocean.

Energia USA (Ref. 16) has indicated that the C-1B external tank geometry has features that can be used as attachment points for a debris capture operation. Referring to Figure 2, a fuel transfer pipe and two vents are located on one side of the Cosmos second stage. The electrical conduits, which are located on either side of the fuel transfer pipe in that figure are approximately $3.5 \mathrm{~m}$ long, $36 \mathrm{~cm}$ deep and $22 \mathrm{~cm}$ wide. In addition, the fuel tank vents are capable of transferring structural loads.

The Cosmos C-1B second stage utilized unsymmetrical dimethylhydrazine and nitrogen tetroxide bipropellant. Its propellant was vented as part of the payload/rocket body separation maneuver, but the venting step did not always occur properly. The propellant tanks utilized 12 $\mathrm{mm}$ thick aluminum skin with $19 \mathrm{~mm}$ thick stringers. Pending final results from the NASA Long Duration Exposure Facility experiments, it should be possible to estimate the likelihood that unvented propellant remains in the tanks, based on micrometeroid penetration predictions. 
Based upon past theoretical studies of the motion of tumbling satellites $/ 15 /$, it can be expected that the C-1B boosters will be tumbling about their principle rotational axes. That is, over time, any rotational energy possessed by an uncontrolled, orbiting object is transferred gradually to the rotational axis with the largest moment of inertia and hence the C-1B's are likely to be tumbling about an axis which is between the rocket motor and the payload mating collar. Consequently, retrieval will require that the debris collector match orbits with the rocket body, then orient itself so that it can be rotated on an axis which is common with the booster's rotational axis (Figure 3a and $\mathrm{b}$ ). Then, the debris collector must achieve rotational synchronization with the tumbling booster before it can be captured. After the two vehicles have been phase-locked with respect to rotation, a pair of robotic arms are envisioned that could grab the C-1B conduits (Figure 3c). A teleoperated system, using a video system that rotated with the platform, would be the most direct approach.

After the arms have captured the booster, the debris collector would be activated to despin the system and then maintain the orientation of the booster while a solid rocket and small strapon control thrusters were positioned and secured in the throat of the RD-119 motor and on the body of the C-1B, respectively (Figure 3d). Subsequently, the booster-solid rocket unit would be oriented for deorbit firing and the debris collector would loiter long enough to make sure that the system was stabilized. At that point, the orbital debris collector would depart for its next target and the C-1B would be launched back into the atmosphere (Figure 3e).

Finally, since ownership of orbiting C-1Bs and possible liability for damages resulting from uncontrolled collisions with other satellites are problematic, international cooperation is an essential element. A joint program to remove such a large population of debris will be necessary to effect a solution within a time frame which will avoid chain-reaction collisions. 


\section{Conclusions}

This study has determined that orbiting Cosmos C-1B booters are both numerous and in orbits at greatest risk for multiple, chain-reaction collisions. By deorbiting the 100 in tact boosters with apogees between 950 and $1050 \mathrm{~km}$, more than $200,000 \mathrm{~kg}$ of material can be removed, avoiding a major potential debris source.

While the mass of material is large enough to warrant studies of how the boosters could be reprocessed in space for other applications, this study has recommended that for the near term these boosters should be deorbited.

\section{Acknowledgement}

This research was sponsored by the University Space Research Association as part of its NASA/USRA Advanced Space System Design Program, managed by Dr. Vicki S. Johnson. 
Table 1

Categorization of Soviet Objects in Orbit, Launched in 1987-88 and with altitudes near $1000 \mathrm{~km}$

\begin{tabular}{|c|c|c|c|c|}
\hline Item & Population & Mass & $\begin{array}{c}\text { Largest } \\
\text { Dimension }\end{array}$ & Comments \\
\hline Large Fragments & 66 & Variable & Variable & $\begin{array}{l}\text { Debris associated with } \\
\text { satellites }\end{array}$ \\
\hline Ferret Satellites & 44 & $40 \mathrm{~kg}$ & $1 \mathrm{~m}$ & Active satellites \\
\hline Rocket Bodies & 29 & variable & variable & Spent Rocket Boosters \\
\hline C-1B & (22) & $2200 \mathrm{~kg}$ & $7.5 \mathrm{~m}$ & $\begin{array}{l}\text { Largest single } \\
\text { population of debris } \\
\text { objects }\end{array}$ \\
\hline Navigation Satellites & 12 & $700 \mathrm{~kg}$ & $1.9 \mathrm{~m}$ & Active satellites \\
\hline Miscellaneous Satellites & 7 & Unknown & Unknown & Not identified \\
\hline $\begin{array}{l}\text { Oceanographic } \\
\text { Satellites }\end{array}$ & 4 & $750 \mathrm{~kg}$ & $2 \mathrm{~m}$ & Active satellites \\
\hline
\end{tabular}




\section{References}

1. Anonymous, "Space Station Program Natural Environment Definition for Design," SSP 30425, Revision A, NASA Space Station Freedom Program Office, Washington, D.C. (June 1991)

2. K. N. R. Ramohalli, "A Robot for Retrieval of Orbital Debris: Hardware Experience," in Proceedings of the Sclera Symposium: Selected Topics in Sciences and Technology and 25th Anniversary Celebration, in press (1992).

3. C. Butner and C. Gartrell, "GRC Orbital Debris Mitigation Systems" Innovative Approaches to Solving Future Problems," AIAA Space Programs and Technologies Conference, Huntsville, AL. AIAA Paper Number 92-1287 (March 1992).

4. L. David, "Satellite Debris Experiment Produces Surprising Results" Space News (Feb. 24-March 1, 1992).

5. D. J. Kessler and B. G. Cour-Palais, "Collision Frequency of Artificial Satellites: The Creation of a Debris Belt" J. of Geophys. Res., 83, \#A6, 2637-2646 (1978).

6. D. J. Kessler, "Collisional Cascading: The Limits of Population Growth in Low Earth Orbit," Advances in Space Research, 11, pp. 63-66, 1991.

7. K. N. R. Ramohalli, et al., "Autonomous Space Processor for Orbital Debris," NASA/University Space Research Association, Summer Design Conference, Huntsville, Alabama; June 1989 (Also U.S. Patent Number 5,120,008, June 9, 1992).

8. K. N. R. Ramohalli, "Economical in situ Processing for Orbital Debris Removal," Acta Astronautica, 26, 55-60 (1992).

9. Anonymous, "Concept Evaluation/Test for the Tumbling Satellite Retrieval Kit, Grumman Corporation, Space Systems Division, Bethpage, NY, NASA Contract NAS 8-36641 (October 1988).

10. Anonymous, "Report on Orbital Debris," Interagency Group (Space) for the National Security Council, Washington, D.C. (February 1989)

11. D. G. King-Hele, et al., The R.A.E. Table of Earth Satellites 1957-1986, Stockton Press, New York, N.Y. (1987).

12. N. L. Johnson, The Soviet Year in Space 1987, Teledyne Brown Engineering, Colorado Springs, Colorado (1988).

13. N. L. Johnson, The Soviet Year in Space 1988, Teledyne Brown Engineering, Colorado Springs, Colorado (1989).

14. C. J. Faranetta, Energia USA, 2214 Rock Hill Rd., Suite 500, Herndon, Virginia 22070, Private Communication (1992).

15. J. E. Cochran, Jr. and B. S. Lahr, Satellite Attitude Motion Models for Capture and Retrieval Investigations, NASA Contractor Report No. NAS8-36470, Marshall Space Flight Center, Alabama (October 1986). 


\section{TARGET LOCATION C-1B ROCKET BODIES}

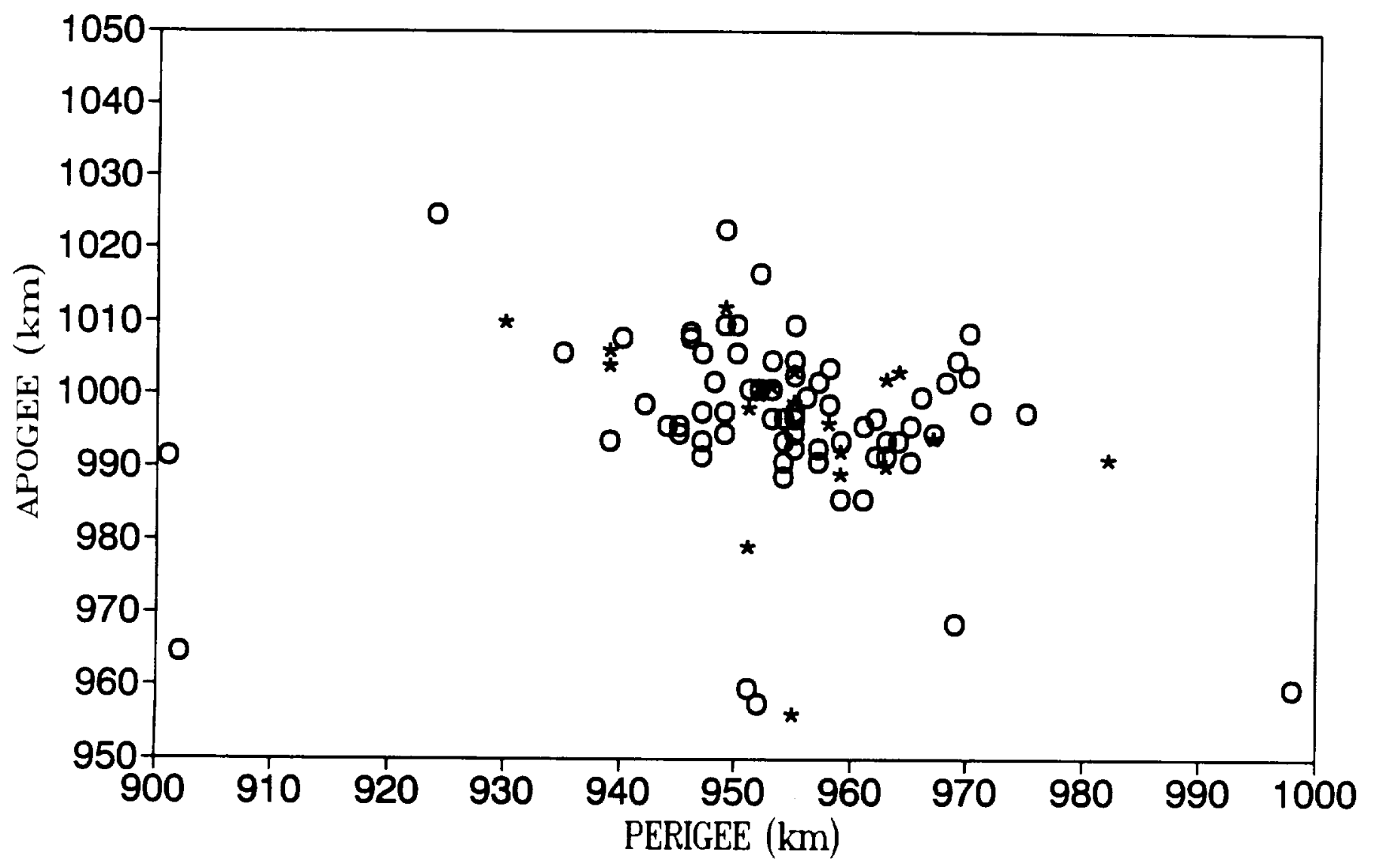

Figure 1 Distribution of orbiting C-1B boosters near $1000 \mathrm{~km}$, at inclinations of $82.9^{\circ}$ (o) and $83.0^{\circ}\left({ }^{*}\right)$ 


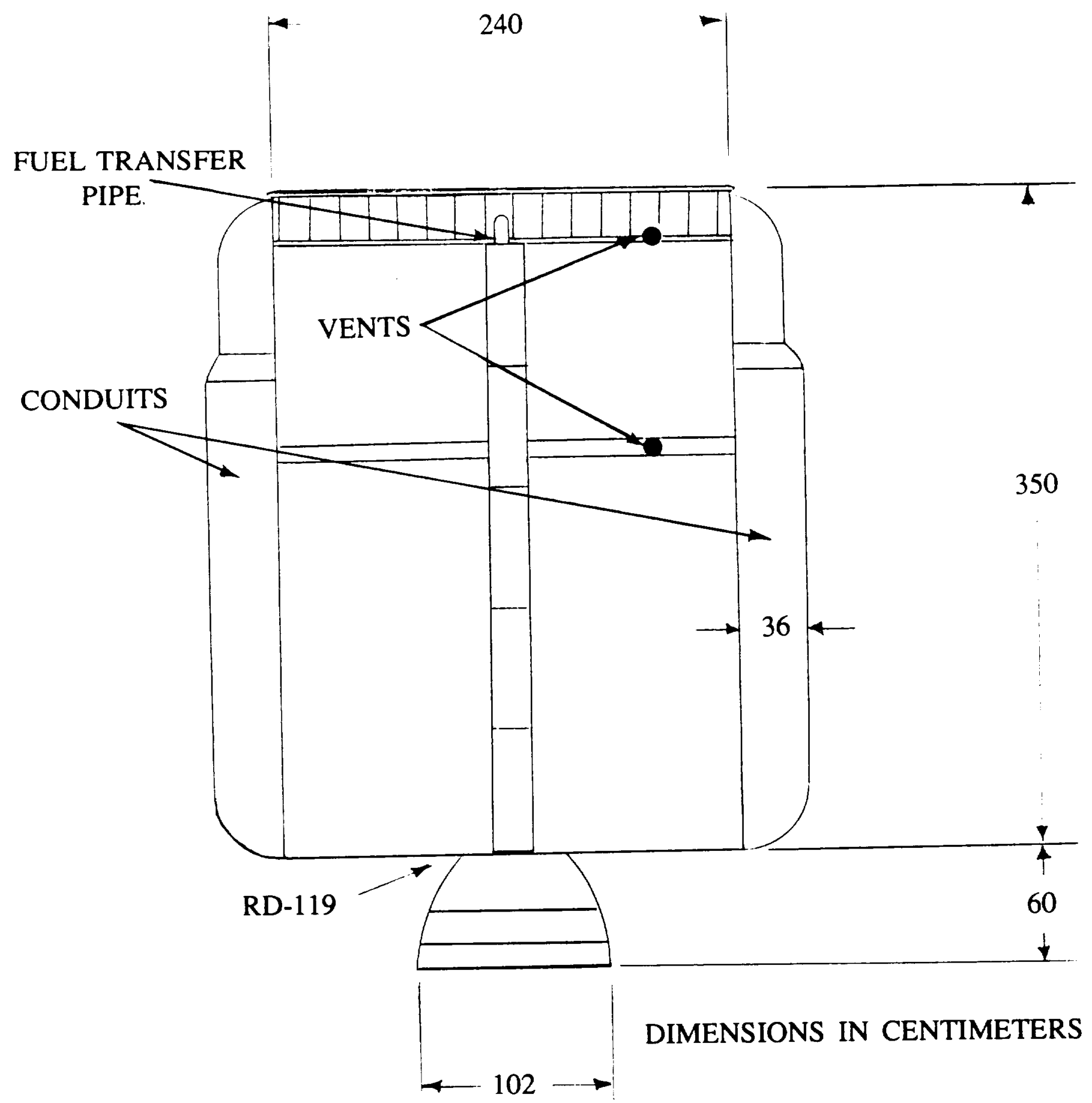

Figure 2 Schematic diagram of C-1B booster geometry 


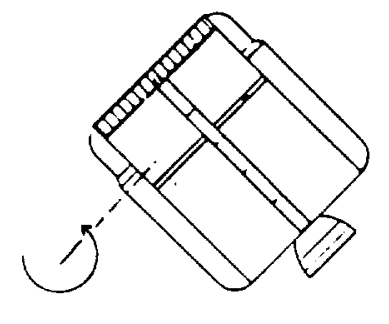

a. Rendezvous

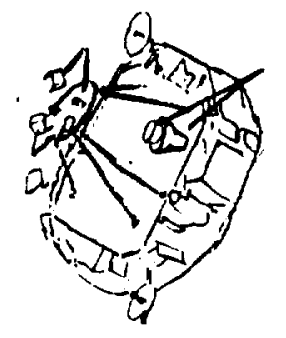

s

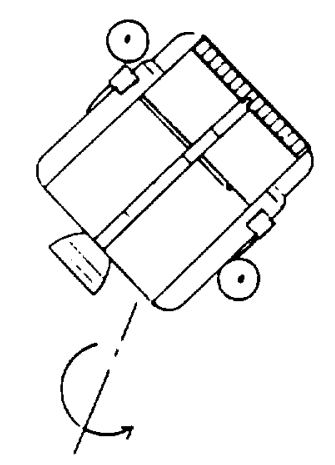

c. Capture

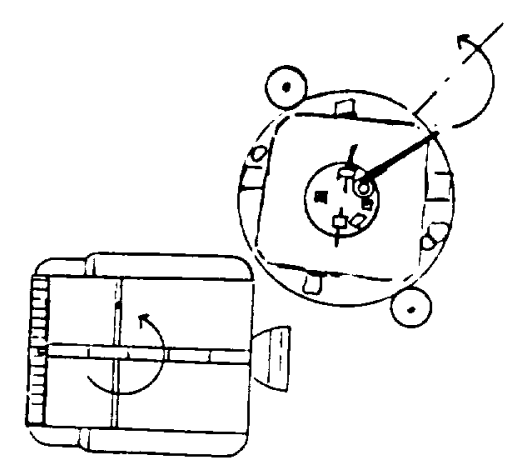

b. Rotational Matching

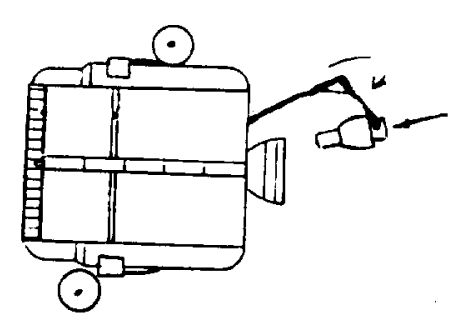

d. Despin and Rocket Insertion
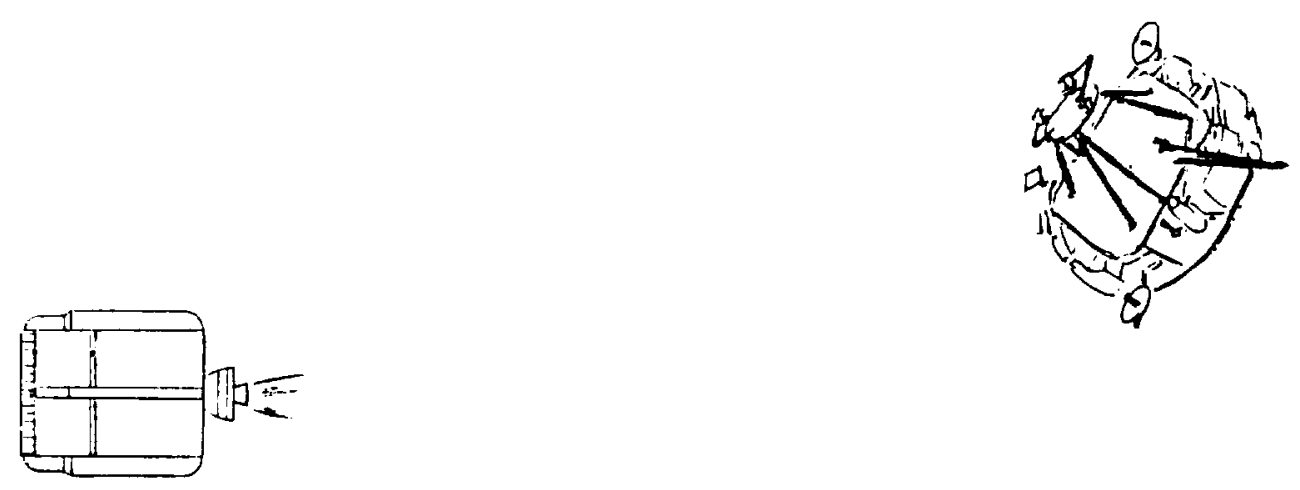

e. Deorbit

Figure 3 Representation of rendezvous and deorbit sequence 